\title{
Occult spontaneous lateral intrasphenoidal encephalocele: A rare presentation
}

\author{
Shahina Bano, Vikas Chaudhary ${ }^{1}$, Sachchida N Yadav², Umesh C Garga ${ }^{2}$ \\ Departments of Radiodiagnosis, Lady Hardinge Medical College and Associated Smt. Sucheta Kriplani and Kalawati Hospitals, New Delhi, \\ ${ }^{1}$ Radiodiagnosis, Employees' State Insurance Corporation Model Hospital, Gurgaon, Haryana, ${ }^{2}$ Radiodiagnosis, Dr. Ram Manohar Lohia \\ Hospital and PGIMER, New Delhi, India
}

\section{ABSTRACT}

Basal encephaloceles are extremely rare congenital malformations. Advanced cross-sectional imaging modalities like computed tomography and magnetic resonance imaging are necessary for diagnosing the asymptomatic, occult basal encephalocele and planning the surgical approach. We present an interesting case of clinically silent right-sided lateral intrasphenoidal encephalocele through a large bony defect.

Key words: Computed tomography, computed tomography/magnetic resonance imaging cisternography, intrasphenoidal encephalocele, magnetic resonance imaging, radionuclide cisternography

\section{Introduction}

Basal encephaloceles are rarely encountered and are most commonly seen in the anterior cranial fossa. They usually present with spontaneous cerebrospinal fluid (CSF) rhinorrhea. Temporal or intrasphenoidal encephaloceles of the middle cranial fossa are very uncommon but do occur, with lateral intrasphenoidal encephalocele being extremely rare. In this report, we present a case of lateral intrasphenoidal encephalocele, highlighting the role of neuroimaging in its diagnosis and planning the surgical approach.

\section{Case Report}

A 37-year-old male patient presented with complaints of transient loss of consciousness and persistent headache after minor head injury. He had no past history of head injury or brain surgery. Neurological examination was normal and there was no stigma of neurofibromatosis.

\begin{tabular}{|l|l|}
\hline \multicolumn{2}{|c|}{ Access this article online } \\
\hline Quick Response Code: & Website: \\
\hline & www.ruralneuropractice.com \\
\cline { 2 - 3 } & \\
\hline & DOI: \\
\hline
\end{tabular}

Plain CT head did not show any brain parenchymal or bony injury. Contrast-enhanced 3-mm axial and coronal CT images of paranasal sinuses [Figure $1 \mathrm{a}$ and $\mathrm{b}$ ] revealed a large (approximately $12 \mathrm{~mm}$ in size) defect in the right lateral wall of the sphenoid sinus with herniation of a part of the right mesial temporal lobe through the defect, to occupy the ipsilateral lateral recess of the sphenoid sinus. The remaining part of the right sphenoid sinus showed mucosal thickening. The bones around the defect and encephalocele showed remodeling and appeared thinned out [Figure 1c and d]. There was no evidence of meningitis or any other intracranial abnormality. CT cisternography was not performed as there was no history of nasal discharge. Further evaluation of the lesion with MRI was not possible because the patient was claustrophobic and refused to undergo sedation.

The surgical exploration confirmed the CT finding of a large bony defect in the right lateral wall of the sphenoid sinus, lateral intrasphenoidal encephalocele occupying the lateral recess with otherwise intact dura. Mild ipsilateral sphenoid sinus mucosal thickening was also documented. Endoscopic transpterygoid approach was used and the herniated brain tissue with intact dura was gently pulled up and the bony defect was closed to prevent future risk of CSF leak, ascending meningitis or brain abscess. The abnormal mucosal thickening was stripped off and space within the right sphenoid sinus was filled with free fat graft. The patient had a good

Address for correspondence:

Dr. Vikas Chaudhary, Department of Radiodiagnosis, Employees' State Insurance Corporation Model Hospital, Gurgaon, Haryana, India. E-mail: dr_vikaschaudhary@yahoo.com 


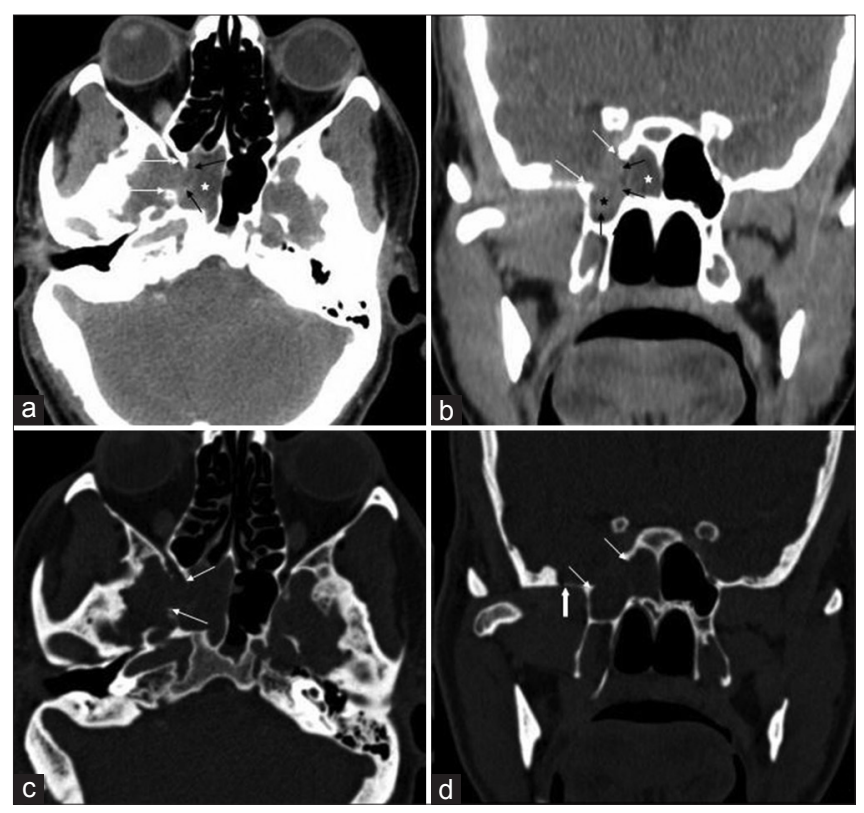

Figure 1: (a, b): Contrast-enhanced axial (a) and coronal (b) CT scan images reveal a large (approximately $12 \mathrm{~mm}$ in size) bony defect in the right lateral wall of the sphenoid sinus (white arrows), with soft-tissue density mass (black arrows) filling the adjacent part of the sphenoid sinus and its lateral recess (black asterisk). Mild ipsilateral sphenoid sinus mucosal thickening is also seen (white asterisk). (c, b): Axial (c) and coronal (d) CT scan images (bone window) show large osseous defect in the right lateral wall of the sphenoid sinus (thin white arrows) and thinning of bones, especially medial part of the greater wing of sphenoid (thick white arrow) adjacent to the defect, as compared with normal left side

postoperative recovery and was advised cross-sectional follow-up study after six months to confirm the integrity of the repair.

\section{Discussion}

Intrasphenoidal encephaloceles are uncommon and can have congenital, iatrogenic, post-traumatic, or spontaneous origin. They are thought to occur most commonly in the central or midline aspect of the sphenoid sinus through the central roof. Lateral intrasphenoidal encephaloceles, especially through the lateral aspect of the sphenoid sinus, within the lateral recess, are extremely rare; and are associated with herniation of the temporal lobe. ${ }^{[1-3]}$ These commonly present in adulthood with or without CSF rhinorrhoea. ${ }^{[3]}$ Other presentations include headache, seizure, meningitis or temporal lobe abscess. ${ }^{[1]}$

Advanced cross-sectional imaging (CT, MRI) are necessary for diagnosing the intrasphenoidal encephalocele and planning the surgical approach. Fine CT cuts through the skull base help to identify the location and size of the bony defect. MRI is superior to CT in identifying neural or vascular tissue present within the herniated sac, and also in detecting other intracranial anomalies associated with encephalocele, if any. In case of active CSF leak, an accurate radiological localization of the site of the fistula should be made; which is, however, challenging in case of intermittent or inactive CSF leaks. CSF leak can be demonstrated by CT cisternography, using cisternal injection of water-soluble contrast medium and localizing the level of the osseous-dural defect. The sensitivity of CT cisternography for diagnosing an active leak is $\sim 80-85 \%$; however, intermittent or inactive fistulas are associated with a high incidence of false negative results. MRI with cisternography or constructive interference in steady-state (CISS: 3D-T2-weighted gradient echo sequence) is commonly used in the diagnosis of CSF fistulas. These flow-sensitive MR imaging studies have been found to be $100 \%$ sensitive in identifying both active and inactive fistulas. ${ }^{[4,5]}$ Radionuclide cisternography, after a lumbar injection of $1.3 \mathrm{mCi}$ 111In-DTPA and using intranasal pledgets can be used to detect occult or intermittent CSF leaks. ${ }^{[6]}$

Treatment of intrasphenoidal encephaloceles is directed towards reduction/amputation of the encephalocele with minimum damage to vital brain tissue and repair of the osseous-dural defect to prevent CSF leak and to decrease the risk of ascending meningitis or brain abscess. Two endoscopic approaches, namely: Transnasal-transethmoidal or transpterygoid approach have been successfully employed in the repair of small intrasphenoidal encephaloceles with CSF leaks. However, larger defects are usually treated via the transcranial route. Small encephaloceles with intact dura and no CSF leakage are followed closely with serial endoscopic examinations and imaging studies and surgical treatment is reserved for encephaloceles expanding in size. Postoperative follow-up with CT scan obtained three to six months after repair is recommended to verify closure of the defect and graft position..$^{[1,7]}$

This case is unique as a clinically silent spontaneous lateral recess intrasphenoidal encephalocele has not been reported in the literature. In addition, a large osseous defect with remodeling of adjacent bones is also rarely encountered. Cross-sectional imaging is particularly useful in careful preoperative evaluation and localization of the sphenoid defect for selection of the optimal surgical approach for repair of the osseous-dural defect.

\section{References}

1. Lai SY, Kennedy DW, Bolger WE. Sphenoid encephaloceles: Disease management and identification of lesions within the lateral recess of the sphenoid sinus. Laryngoscope 2002;112:1800-5.

2. Jabre A, Tabaddor R, Samaraweera R. Transsphenoidalmeningoence phalocele in adults. Surg Neurol 2000;54:183-7. 
Bano, et al.: Lateral intrasphenoidal encephalocele

3. Pandey AK. Case report: Anteromedialtemporosphenoidalencephalocele with a clinically silent lateral bony defect in the greater wing of the sphenoid. Indian J Radiol Imaging 2009;19:311-3.

4. Johnson DB, Brennan P, Toland J, O’Dwyer AJ. Magnetic resonance imaging in the evaluation of cerebrospinal fluid fistulae. Clin Radiol 1996;51:837-41.

5. Levy LM, Gulya AJ, Davis SW, Le Bihan D, Rajan SS, Schellinger D. Flow-sensitive magnetic resonance imaging in the evaluation of cerebrospinal fluid leaks. Am J Otol 1995;16:591-6.

6. Oberson R. Radioisotopic diagnosis of rhinorrhoea. Radiol Clin Biol
1972;41:28-35.

7. Bimaz K, Cosar M, Iplikcioglu AC, Dinc C, Hatiboglu MA. Spontaneous cerebrospinal fluid rhinorrhoea due to temporal encephalocele. J Clin Neurosci 2005;12:827-9.

How to cite this article: Bano S, Chaudhary V, Yadav SN, Garga UC. Occult spontaneous lateral intrasphenoidal encephalocele: $A$ rare presentation. J Neurosci Rural Pract 2013, 4(Suppl 1):s109-11.

Source of Support: Nil. Conflict of Interest: None declared. 